\title{
A Sex-linked Disorder with Mental and Physical Retardation Characterized by Cerebrocortical Atrophy and Increase of Glutamic Acid in the Cerebrospinal Fluid
}

\author{
By \\ Toshio Yoshida, Keiya Tada, Takashi Mizuno, Yoshiro Wada, \\ Jinzo Akabane, Jiro Ogasawara, Akibumi Minagawa, \\ Toshio Morikawa and Toshihiro Okamura \\ From the Department of Pediatrics, Faculty of Medicine, Tohoku \\ University, Sendai; Director: Prof. Ts. A r a k a wa \\ (Received for publication, May 12, 1964)

\begin{abstract}
A case of mental and physical retardation inherited as a sex-linked recessive trait is presented. Laboratory findings revealed an elevated level of glutamic acid, diminished level of glutamine in the cerebrospinal fluid, mild generalized aminoaciduria and galactosuria. Pneumoencephalogram indicated a remarkable atrophy of the cerebral cortex.
\end{abstract}

Pedigrees of mental defect showing sex-linked inheritance have been reported by Paine ${ }^{1)}$ and Menkes et $a l^{2}$. It is unknown whether or not these cases belong to the single entity, although clinical symptoms and signs are similar.

This paper describes a case of sex-linked inheritance of mental and physical retardation with special emphasis on our finding of elevated level of glutamic acid in the cerebrospinal fluid.

\section{CASE REPORT}

Family history: The parents are healthy and not consanguineous. There are no siblings. An uncle, two male first cousins, and a male cousin once removed, on the maternal side, died in infancy or childhood showing physical and mental retardation similar to the patient (cf. Fig. 1). There is no history of such a disorder on the paternal side. These histories suggest that the condition is transmitted by a sex-linked inheritance.

Past history: The patient, a male, was born at full term after a normal

吉田稔男, 多田啓也, 水野 隆, 和田義郎, 赤羽仁三, 小笠原二郎, 皆川明文, 森川利夫

岡村敏弘 


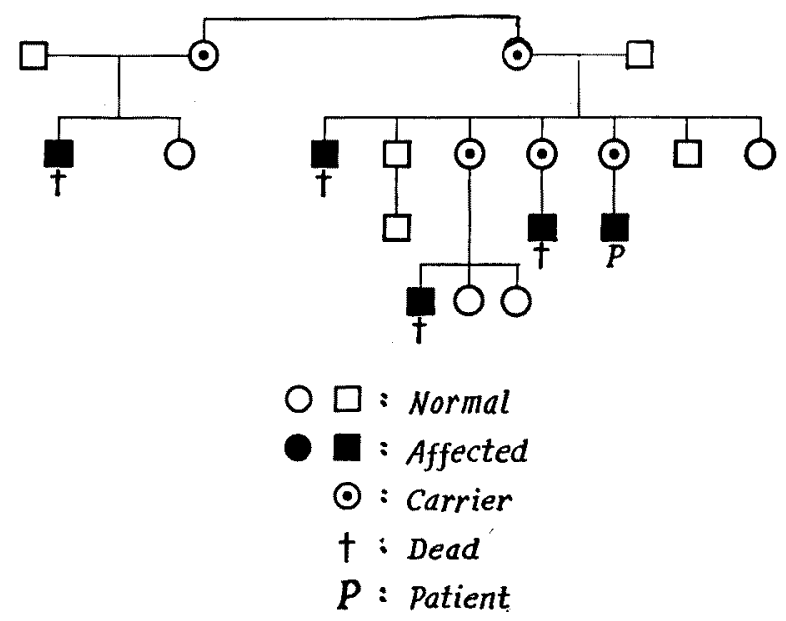

Fig. 1. Pedigree of the patient.

pregnancy and delivery, weighing $2,900 \mathrm{~g}$. His neonatal period was uneventful with a normal course of physiologic jaundice. He was fed on mixed feeding.

Present illness: At about three months of age, his mother noticed a poor gain in weight of the patient. At the age of 10 months, he was admitted to our Clinic because of retardation of mental and physical development. He had no history of convulsions.

On admission, physical examination revealed a poorly nourished boy with an apathetic countenance. Height was $71.0 \mathrm{~cm}$, body weight $7.4 \mathrm{~kg}$, circumference of the head $43 \mathrm{~cm}$; these figures were smaller than those of the normal. He appeared to take no notice of his surroundings. He did not grab or reach after objects, hold up his head, roll over or sit. He was able to follow the light and to react to auditory stimulations. There was only minimal response to painful stimuli.

The pupils reacted to light and the fundi showed no abnormalities. Moderate strabismus and high arched palate were noted. The lungs and heart were clear to auscultation. Neither the liver nor the spleen was palpable. There was no lymphadenopathy. The extremities were somewhat rigid and the deep tendon reflexes were hyperactive. No pathological reflexes were elicited.

Laboratory findings: Routine blood studies and determination of chemical constituents, including serum protein and its electrophoretic pattern, serum electrolytes, serum lipids and nonprotein nitrogen, were within normal limits. Liver function tests also were normal.

The urine was clear with $\mathrm{pH}$ of 6.2 and negative for protein, acetone, bilirubin or phenylpyruvic acid. Urobilinogen excretion was within normal limits. Nylander's and Benedict's reactions for sugar in the urine were in most cases positive. But Testape test for glucose was negative. The sugar respons- 
ible for positive Nylander's and Benedict's reactions was identified as galactose by paperchromatography.

Both the tuberculin and Wassermann tests were negative. X-ray films of the skull, chest, abdomen and bones revealed no abnormality.

\section{2 <6 68 11.11 \\ 8123281868382 $\times \quad 6 \quad 12$}

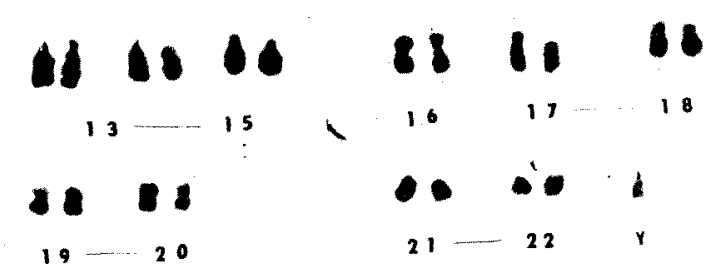

Fig. 2. Karyotype of chromosomes from the patient.

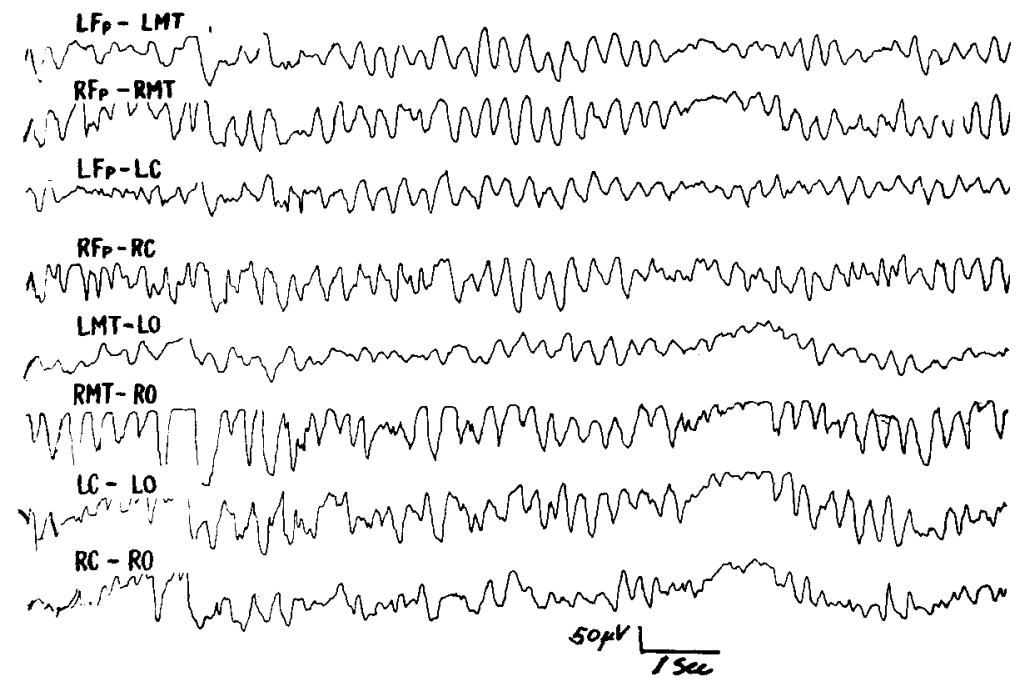

Fig. 3. Electroencephalogram of the patient. 
Normal cerebrospinal fluid was obtained by lumbar puncture. Its chromatographic findings will be described later.

Chromosomal analysis showed no abnormality in both number and configuration (cf. Fig. 2).

Electroencephalographic findings: Resting record showed an occurrence of HVS (3-4 c/s) in all leads (cf. Fig. 3). Sleep activation revealed a slight dysrhythmia but neither paroxysmal discharge nor asymmetry was detected. No epileptic discharges were elicited by photic stimulations.

Pneumoencephalographic findings showed a remarkable atrophy mainly in the cortex of the left parietal and right frontal lobes. Enlargement of the lateral ventricles was observed bilaterally (cf. Fig. 4). Cerebral angiographic findings
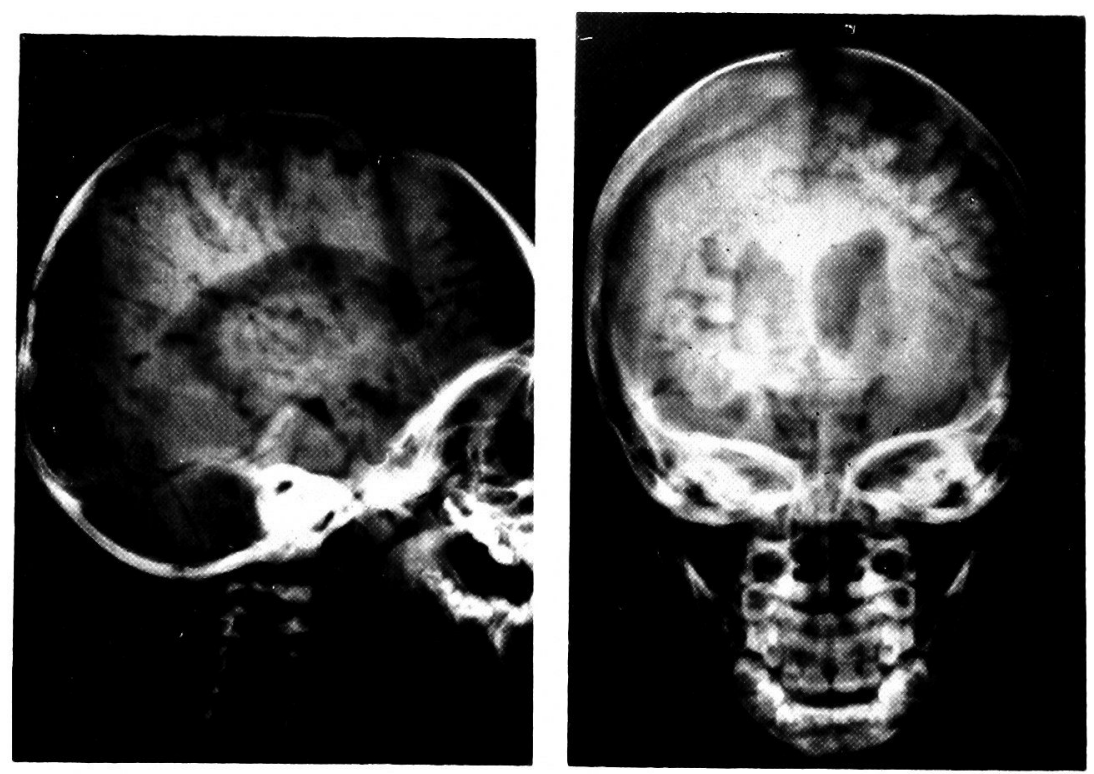

Fig. 4. Pneumoencephalograms of the patient.

Enlargement of the lateral ventricles and atrophy of the left parietal and right frontal lobes were noted.

showed no abnormalities. This means that cortical atrophy was not due to anomaly or injury of cerebral arteries.

Amino acid analyses: The urine, serum and cerebrospinal fluid were subjected to amino acid analyses.

The paperchromatography of urinary amino acids was made by Ghadimi's $\operatorname{method}^{3)}$. Quantitative estimation of free amino acid nitrogen (amino N) was made by Tada's method ${ }^{4}$.

Paperchromatogram of urine specimens of the patient revealed a mild 
generalized aminoaciduria (cf. Fig. 5). Serum amino $\mathrm{N}$ was found to be $5.2 \mathrm{mg}$ per $100 \mathrm{ml}$ and urinary amino $\mathrm{N}$ to be $54.1 \mathrm{mg}$ per day.

Paperchromatogram of the cerebrospinal fluid showed an increased level of glutamic acid.

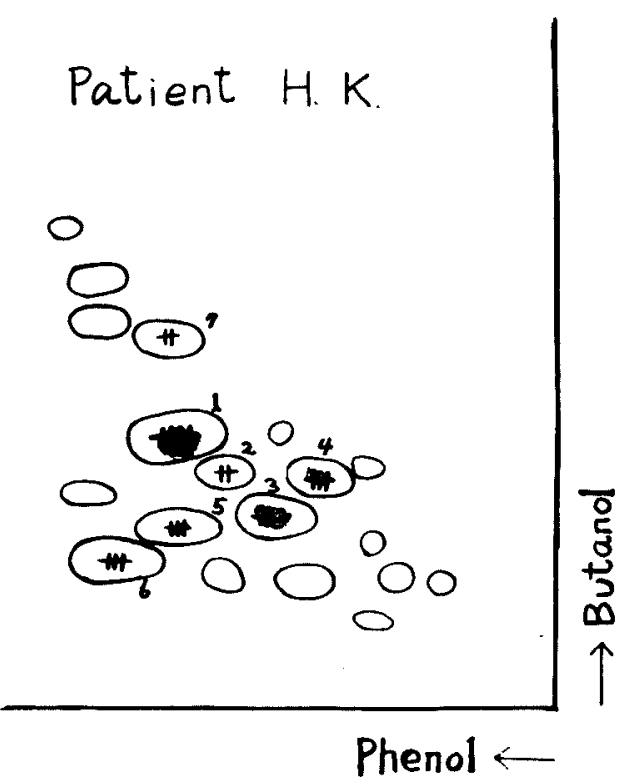

Fig. 5. Paperchromatogram of urinary amino acids.

Keys: 1. alanine, 2. threonine, 3. serine \& glycine,

4. glutamic acid, 5. glutamine, 6. histidine,

7. tyrosine

Serum amino acid pattern analyzed by automatic amino acid analyzer (Beckman-Spinco type) showed slightly high levels of glutamic acid, proline and leucine (cf. Table I).

Amino acid pattern in the cerebrospinal fluid by automatic amino acid analyzer showed an increased level of glutamic acid and a decreased level of glutamine. For convenience' sake, the ratio of glutamine to glutamic acid (G/ GA ratio) in the cerebrospinal fluid was calculated. The ratio in the patient was ranging from 4.61 to 8.50 and these figures were remarkably lower than those in the controls (cf. Table II).

Glutamic acid loading test: Ten $\mathrm{ml}$ of $10 \%$ sodium glutamate were intravenously injected. Serum specimens obtained before and one hour after the loading were investigated for glutamic acid level. There was no rise in serum glutamic acid one hour following the loading both in the patient and a control individual (cf. Table III). 
Table I. Serum Amino Aoid Levels $(\mu$ moles $/ l)$

\begin{tabular}{l|c|r|r}
\hline & \multirow{2}{*}{ Patient } & \multicolumn{2}{|c}{ Normal range } \\
\cline { 2 - 4 } & & Average & \multicolumn{1}{|c}{ Range } \\
\hline Aspartic acid & Not detectable & & $0-36$ \\
Threonine & 123 & $58 \pm 16$ & $31-88$ \\
Serine* & 304 & $246 \pm 42$ & $187-328$ \\
Glutamic acid & 168 & $93 \pm 30$ & $45-149$ \\
Proline & 248 & $155 \pm 44$ & $88-236$ \\
Glycine & 339 & $235 \pm 57$ & $164-386$ \\
Alanine & 524 & $313 \pm 112$ & $146-552$ \\
Valine & 245 & $159 \pm 42$ & $80-245$ \\
Isoleucine & 72 & $46 \pm 12$ & $21-72$ \\
Leucine & 130 & $88 \pm 15$ & $60-117$ \\
Tyrosine & 42 & $42 \pm 13$ & $20-69$ \\
Phenylalanine & 34 & $46 \pm 12$ & $30-69$ \\
Histidine & 43 & $36 \pm 14$ & $21-68$ \\
Lysine & 188 & $156 \pm 57$ & $75-256$ \\
& & &
\end{tabular}

* The value for serine was expressed as the sum of serine and glutamine because both fractions were not sharply separated.

TABLE II. Levels of Glutamic Acid and Glutamine in Cerebrospinal Fluid

\begin{tabular}{c|c|c|c}
\hline & $\begin{array}{c}\text { Glutamic acid } \\
(\mu \text { moles } / l)\end{array}$ & $\begin{array}{c}\text { Glutamine } \\
(\mu \text { moles } / l)\end{array}$ & $\begin{array}{c}\text { Ratio of glutamine } \\
\text { to glutamic acid }\end{array}$ \\
\hline \multirow{2}{*}{ Patient } & 60.4 & 278 & 4.61 \\
& 35.3 & 300 & 8.50 \\
\hline A & 5.0 & 405 & 81.0 \\
B & 8.9 & 250 & 28.6 \\
C & 7.5 & 348 & 46.4 \\
节 & 16.4 & 381 & 23.2 \\
E & 17.7 & 337 & 18.8 \\
F & 15.6 & 355 & 22.8 \\
Average & 11.9 & 346 & 36.8
\end{tabular}

Table III. Glutamic Acid Loading Test

\begin{tabular}{c|c|c}
\hline & \multicolumn{2}{|c}{ Serum glutamic acid $\mathrm{mg} / 100 \mathrm{ml}$} \\
\cline { 2 - 3 } & Before loading & One hour following loading \\
\hline Patient & 1.76 & 1.58 \\
Control & 0.86 & 0.77
\end{tabular}

Note: $10 \mathrm{ml}$ of $10 \%$ sodium glutamate were administered intravenously.

Blood sugar level was within normal limits and galactose tolerance test indicated a normal curve. Schwarz's test ${ }^{5)}$ showed no accumulation of galactose-1phosphate in the erythrocytes from the patient. The results of these findings 
excluded the possibility of galactosemia.

\section{DISCUSSION}

The characterisitic findings of our own patient can be summarized as follows.

1. The disorder seems to be of sex-linked recessive inheritance.

2. Abnormally elevated level of glutamic acid and relatively diminished level of glutamine in the cerebrospinal fluid are found.

3. Galactose is excreted in the urine.

4. Atrophy in cerebral cortex is remarkable.

In sex-linked recessive inheritance, heterozygous females will transmit the mutant gene to half their sons, who will be affected, and half their daughters, who will be carriers. Among such inherited diseases, hemophilia and progressive muscular dystrophy are commonly known, but the cases with mental and physical retardation are very rare. Such cases were only reported by Paine ${ }^{1)}$ and Menkes

TABLE IV. Comparative View of Clinical and Laboratory Findings in Paine's, Menkes et al.'s and Our Own Cases

\begin{tabular}{|c|c|c|c|}
\hline & Paine's case & Menkes et al.'s cases & Our own cases \\
\hline $\begin{array}{l}\text { Development } \\
\text { Physical } \\
\text { Mental }\end{array}$ & $\begin{array}{l}\text { Retarded } \\
\text { Retarded }\end{array}$ & $\begin{array}{l}\text { Retarded } \\
\text { Retarded }\end{array}$ & $\begin{array}{l}\text { Retarded } \\
\text { Retarded }\end{array}$ \\
\hline Convulsion & $\begin{array}{l}\text { Absent except once } \\
\text { before death }\end{array}$ & Present & Absent \\
\hline Microcephalus & Present & Present & Present \\
\hline Extremities & Spastic & Spastic & Spastic \\
\hline Scalp hair & N.D.* & Sparse & Sparse \\
\hline EEG & Diffusely abnormal & $\begin{array}{l}\text { Spikes and slow waves } \\
\text { in either hemisphere }\end{array}$ & Diffusely HVS \\
\hline PEG & N.D. & $\begin{array}{l}\text { Enlargement of the } \\
\text { right lateral ventricle } \\
\text { attributed to atrophy } \\
\text { of the right frontal } \\
\text { lobe }\end{array}$ & $\begin{array}{l}\text { Enlargement of the } \\
\text { lateral ventricles } \\
\text { attributed to atrophy } \\
\text { of the cerebral cortex }\end{array}$ \\
\hline Age of death & 1 year 5 months & 11 months $-3 \frac{1}{2}$ years & Living \\
\hline Autopsy & $\begin{array}{l}\text { Cerebellar hypoplasia, } \\
\text { and diminishing } \\
\text { neurons in the } \\
\text { cerebrum }\end{array}$ & $\begin{array}{l}\text { Atophy and degenera- } \\
\text { tion of the cerebral } \\
\text { cortex }\end{array}$ & \\
\hline Aminoaciduria & $\begin{array}{l}\text { Mild, generalized } \\
\text { pattern }\end{array}$ & $\begin{array}{l}\text { Mild, generalized } \\
\text { pattern }\end{array}$ & $\begin{array}{l}\text { Mild, generalized } \\
\text { pattern }\end{array}$ \\
\hline $\begin{array}{l}\text { Serum amino } \mathrm{N} \\
\text { glutamic acid }\end{array}$ & $\begin{array}{c}1.8 \mathrm{mg} / 100 \mathrm{ml} \\
\text { N.D. }\end{array}$ & $\begin{array}{l}\text { N.D. } \\
\text { Increased }\end{array}$ & $\begin{array}{l}5.2 \mathrm{mg} / 100 \mathrm{ml} \text {. } \\
\text { Slightly increased }\end{array}$ \\
\hline $\begin{array}{l}\text { Glutamic acid } \\
\text { in the cerebro- } \\
\text { spinal fluid }\end{array}$ & N.D. & N.D. & Markedly increased \\
\hline
\end{tabular}

* N.D. : no description 
et al. ${ }^{2)}$ up to date.

Table IV shows characteristic findings of these cases in comparison with those of our own case. There are many common findings among these cases, for example, physical and mental retardation, microcephalus, spasticity of the limbs and mild generalized aminoaciduria. In Menkes et al.'s cases, an enlargement of the ventricle attributed to atrophy of the cerebral cortex was found by pneumoencephalography and autopsy. In our patient also the similar findings were recognized by pneumoencephalography. Menkes et al. found an increase of glutamic acid in serum in their patients. This finding also is in agreement with that of our patient. However, in Paine's and Menkes et al.'s reports there is no description of quantitative analysis of glutamic acid or glutamine in the cerebrospinal fluid which is a noticeable finding in our patient.

These cases including our case, we suppose, may constitute a clincial entity which is characterized by sex-linked inheritance and atrophy of cerebral cortex, although Menkes et al. stated difference of their cases from the Paine's case.

In our own findings, a deviation of the G/GA ratio in the cerebropsinal fluid from the patient, is worthy of notice. It is well known that the brain contains dominantly glutamic acid among free amino acids and that glutamic acid metabolism, including its pathway to glutamine, aspartic acid or $\gamma$-aminobutyric acid, is closely related to brain function. It is difficult to understand why such a deviation of the G/GA ratio takes place in our patient. But we may say that the deviation of the ratio in the cerebrospinal fluid is a reflexion of some disturbance in glutamic acid metabolism in the brain.

Is the metabolic disturbance of glutamic acid to be supposed a primary lesion of the disorder or a consequence of cerebral atrophy? This question is open to be solved. Even if the disturbance is primary or secondary, an increase in glutamic acid and a decrease in glutamine in cerebrospinal fluid lead our attention to the pathway of glutamic acid to glutamine. In the brain, glutamine is formed from glutamic acid and ammonia by glutamine synthetase ${ }^{6,7}$. Producttion of ammonia by the brain tissue is remarkable, in process of glutamic acid ${ }^{8}$ ) to $\gamma$-aminobutyric acid or of other pathway as compared with other organs ${ }^{6,9,10}$ ) and its detoxication is thought to be mainly carried out through the pathway of glutamic acid to glutamine ${ }^{11)}$. It might be, therefore, presumed that the deviation of the $\mathrm{G} / \mathrm{GA}$ ratio reflects a disturbance in detoxicating system of ammonia. If such were the case, there would be a possibility that atrophy of the brain is the result of the disturbance in ammonia detoxication.

Blood ammonia level in our patient was within normal limits. This indicates that detoxication of ammonia in the liver is intact.

The significance of galactosuria in the patient is obscure. According to Kawamoto ${ }^{12}$, the children with brain damage such as cerebral palsy or postencephalitic sequelae excrete frequently galactose in urine. Probably galactosuria 
observed in our patient is the secondary phenomenon due to cerebral dysfunction.

\section{References}

1) Paine, R.S., New Engl. J. Med., 1960, 262, 658.

2) Menkes, J.H., Alter, M., Steigleder, G.K., Weakley, D.R. \& Sung, J.H., Pediatrics, 1962, 29, 764.

3) Ghadimi, H. \& Schwachmann, H., Amer. J. Dis. Child., 1960, 99, 457.

4) Tada, K., Pediatrica Japonica, 1958, 1, 2, 1.

5) Schwarz, V. \& Holzel, A., Lancet, 1958, 1, 24.

6) Krebs, H.A., Biochem. J., 1935, 29, 1151.

7) Speck, J.F., J. Biol. Chem., 1949, 179, 1405.

8) Takagaki, G., J. Biochem., 1955, 42, 31.

9) Vrba, R., J. Neurochem., 1957, 1, 12.

10) Weil-Malherbe, H. \& Green, C.H., Biochem. J., 1955, 61, 210.

11) DuRuisseau, J.P., Greenstein, J.P., Winitz, M. \& Birnbaum, S.M., Arch. Biochem. Biophys., 1957, 68, 161.

12) Kawamoto, T., Osaka Shiritsudaigaku Igakuzasshi (Jap.), 1960, 9, 147. 